http://jmscr.igmpublication.org/home/

ISSN (e)-2347-176x ISSN (p) 2455-0450

crossref DOI: https://dx.doi.org/10.18535/jmscr/v7i12.102

Journal Of Medical Science And Clinical Research

IGM Publication

An Official Publication of IGM Publication

\title{
Study to Assess the Association between Sleep Duration and Prevalence of Overweight/Obesity
}

\author{
Authors \\ Dr Achla Jain ${ }^{1}$, Dr Neera Mrathe ${ }^{2}$, Dr Prayank Jain ${ }^{2 *}$, Dr Anvita Mishra ${ }^{3}$ \\ Dr Anjana Niranjan ${ }^{3}$ \\ ${ }^{1}$ Third year Post Graduate Student, Department of Community Medicine, SSMC Rewa \\ *Corresponding Author \\ Dr Prayank Jain, DM Cardiology
}

\begin{abstract}
Background: Sleep disturbance has been shown to cause metabolic and endocrine alternations. Sleep has been known to influence the physical and emotional well being of adolescents by causing substantial biological and psychosocial changes. According to recent estimates, the worldwide prevalence of obesity has doubled since 1980. Lack of adequate sleep predisposes overweight and obesity. Growing evidence suggests that short sleep duration is a risk factor for obesity and its complications.

Objective: The objective was to investigate the association between self-reported usual sleep duration and the prevalence of overweight and obesity among the adolescents of Rewa city, M.P.

Material and Methods: A cross-sectional community-based study was conducted among 744 adolescents aged 10-19 years from Rewa city M.P. India using modified questionnaire and standardized anthropometric measures through house-to-house visits. Data was entered in Microsoft Excel sheet, analysed and interpreted using descriptive statistics.

Results: In our study significantly higher prevalence of overweight/obesity was found among subjects sleeping < 6hours as compared to those sleeping 6 to 8 hours in night.

Conclusion: Short sleep duration would get exaggerated with increase in weight gain and incident overweight/obesity. Further research is needed to understand the mechanisms by which sleep duration may affect weight.
\end{abstract}

Keywords: sleep, overweight, adolescents.

\section{Introduction}

Obesity is the main determinant of preventable burden of diseases. ${ }^{1}$ Globally at the other end of the malnutrition obesity is emerging as a today's most blatantly visible yet most neglected public health problems. Obesity is a complex condition, having serious social and psychological dimensions, that affects virtually all age and socioeconomic groups and threatens to overwhelm both developed and developing countries. ${ }^{2}$ In recent years prevalence of childhood obesity has risen globally. The International Association for the Study of Obesity (IASO) and International Obesity Task Force (IOTF) estimate that 200 million school children are either overweight or obese. ${ }^{3}$ The evidence offers a discouraging prediction with the fact that chance of an obese teen becoming an obese adult is as high as $80 \%{ }^{4}$ 
Obesity and poor sleep are concurrent epidemics in youth. Of the modern living Inadequate or unsatisfactory sleep is becoming a serious health issue. For a healthy living sleep is one of the basic necessities. Good and adequate sleep improves the quality of life. Sleep helps the brain to work properly, improve memory and provide longevity. An adequate amount of sleep improves ability to function and feel well while awake.

Many factors like meeting academic deadlines and hectic school schedules are the major factors that interfere with normal sleep patterns among adolescents. Adolescents don't recognize importance of sleep, some of them view the sleeping time as wasted time and consciously disregard the need for sleep, these all are at risk for sleep disturbance. However, the fact is that for optimal functioning of the body sleep is essential, it helps to restore and maintain normal functioning of the immune, endocrine, nervous, skeletal, and muscular systems. ${ }^{5}$ Thus, sleep deprivation may result in disturbances pertaining to these systems and arises many negative consequences which include irritability, exhaustion, lack of concentration, and impaired judgment etc.

Recent studies conducted in various parts of the world indicate that besides conventional factors like physical activity, dietary habit and genetic inheritance, sleep has evolved as a significant determinant of body composition. ${ }^{6,7,8}$

Globally the prevalence of sleep deprivation is rising alarmingly. ${ }^{9,10,11}$ as is that of obesity. Likewise, the 2004-2007 National Health Interview Survey had found approximately $28.3 \%$ of adults sleeping $6 \mathrm{~h}$ or less per night. Sleep deprivation is experienced by $45 \%$ of children ages 11-17 years and $37 \%$ of adults. ${ }^{5}$ As per American sleep association Sleep Deprivation Statistics $35.3 \%$ adults report $<7$ hours of sleep during a typical 24-hour period and 100,000 deaths occur each year in US hospitals due to medical errors and sleep deprivation have been shown to make a significant contribution. $^{12}$
Table 1: Poor sleep and obesogenic behaviours proposed mechanisms. ${ }^{13}$

- Decreased Leptin

- Increased Ghrelin

- Evening Chronotype

- Early awake time

- Social jetlag

- Bedtime Shift

- Hormonal Alterations

- Unhealthy Food Choice

- Sugar-sweetened beverages

- Fast food

- High calorie snacks

- Increased food consumption

- Increased perceived hunger

- Food preoccupation

Alterations in these hormone levels may lead to increases in subsequent caloric intake and weight gain. Sleep restriction also has been shown to alter carbohydrate metabolism, resulting in increased insulin resistance and impaired glucose tolerance, which may also affect weight status. ${ }^{14,15}$

The cumulative effects of chronic sleep deprivation and sleep disorders have been associated with increased mortality and increased risk for a wide range of chronic diseases including depression, hypertension, stroke, type 2 diabetes, heart disease, and obesity. ${ }^{16}$

Till date no study has been published as original research in various indexing agencies, which showing information and awareness about the association between lack of sleep and obesity among adolescents of Madhya Pradesh. Hence, by keeping all these fact in mind the present study is carried out at Rewa city.

\section{Material and Method}

A cross-sectional community-based study was conducted conducted among 744 adolescents aged 10-19 years in Rewa city from January to December 2018 after approval of institutional ethical committee. Primarily this community based study was carried out to find out prevalence of overweight and obesity among adolescents with sleep deprivation as one of its associated factor. 
Hence, Sample size was determined by taking combined prevalence of overweight and obesity among adolescents of India found to be $19.3 \%$ by a systematic review of various studies conducted after 2010 with keeping specified relative precision $15 \%$ at $95 \%$ confidence interval. Sample size was estimated according to formula $\mathrm{n}=\mathrm{Z} 21$ $\alpha / 2 \mathrm{p}(1-\mathrm{p}) / \mathrm{d} 2$ Thus, sample size estimated was 744.

A stratified random sampling procedure was adopted for the selection of study subjects. Ward list was obtained by Municipal Corporation and then these wards are divided into urban, periurban and slum areas. Then randomly three wards were selected from each area, so nine wards were selected randomly. House listing from each selected ward was carried out. A team had went to the centre of the ward and then proceeded in all the directions. In each ward, house-to- house survey was undertaken till $83 / 82$ subjects of 10 to 19 years age group were selected from each ward to complete sample size.

Thus 744subjects who gave informed consent included in the study while Subjects not able to participate due to severe illness and those were absent in the day of visit were excluded. Study subjects were assured of confidentiality and anonymity. The data was collected by researcher using semi-structured questionnaire and study subjects were called to a separate room to take their anthropometric measurements.

\section{Criteria for Overweight and Obesity and Sleep Deprivation}

1. According to guidelines suggested by the National Sleep Foundation, insufficient sleep, defined as $<8$ hours for children's and $<7$ hours for adults on a week night regardless of environmental or cultural differences. ${ }^{6}$

2. Centers for Disease Control and Prevention (CDC) growth chart were applied to identifying the age- and genderspecific cut-off points for the labelling of overweight and obesity among the included subjects. Overweight is defined as children with BMI value between $85^{\text {th }}$ to $95^{\text {th }}$ percentile for a specific age and sex. Similarly obesity is defined as children with a BMI value above $95^{\text {th }}$ percentile, while <5th percentile were considered "Underweight" for a specific age and sex. $^{17}$

\section{Statiscal Analysis}

Data was entered in Microsoft Excel spread sheet, analysed and interpreted using Descriptive statistics. Chi square test of significance was used to find out the association. $\mathrm{P}$ value of less than 0.05 was considered statistically significant

\section{Results}

In our study, 744 adolescents of age group 10-19 years were included to find out association between sleep duration and overweight/obesity. The study population comprised of 385 males $(51.7 \%)$ and $359(48.3 \%)$ females.

Prevalence of overweight/obesity was found to be 21.9\% (Table 2). Amongst the subjects who were sleeping $<6 \mathrm{hr},(33.6 \%)$ were over-weight/obese , $21.6 \%$ were over-weight/obese among those, who were sleeping 6-7 hr, while only $14.5 \%$ were over-weight/obese among those sleeping $\geq 8 \mathrm{hr}$. Significant $(P=0.000307)$ association was found between short sleep duration and prevalence of overweight/obesity among study subjects. (Table 2). 


\section{JMSCR Vol||07||Issue||12||Page 580-587||December}

Table 2: Association of overweight and obesity with duration of sleep at night

\begin{tabular}{|c|c|c|c|c|c|}
\hline $\begin{array}{l}\text { Duration of night } \\
\text { sleep (hours) }\end{array}$ & $\begin{array}{c}\text { Under-weight / } \\
\text { Normal } \\
(\%)\end{array}$ & $\begin{array}{c}\text { Over-weight } \\
(\%) / \text { Obese } \\
(\%)\end{array}$ & $\begin{array}{l}\text { Total } \\
(\%)\end{array}$ & $\chi^{2}$ & P value \\
\hline$<6 \mathrm{hr}$ & $\begin{array}{c}85 \\
(66.4)\end{array}$ & $\begin{array}{c}43 \\
(33.6)\end{array}$ & 128 & \multirow{4}{*}{16.1765} & \multirow{4}{*}{0.000307} \\
\hline $6-7 \mathrm{hr}$ & $\begin{array}{c}337 \\
(78.4) \\
\end{array}$ & $\begin{array}{c}93 \\
(21.6)\end{array}$ & 430 & & \\
\hline$\geq 8 \mathrm{hr}$ & $\begin{array}{c}159 \\
(85.5)\end{array}$ & $\begin{array}{c}27 \\
(14.5)\end{array}$ & 186 & & \\
\hline $\begin{array}{l}\text { Total } \\
(\%)\end{array}$ & $\begin{array}{c}581 \\
(78.1)\end{array}$ & $\begin{array}{c}163 \\
(21.9)\end{array}$ & 744 & & \\
\hline
\end{tabular}

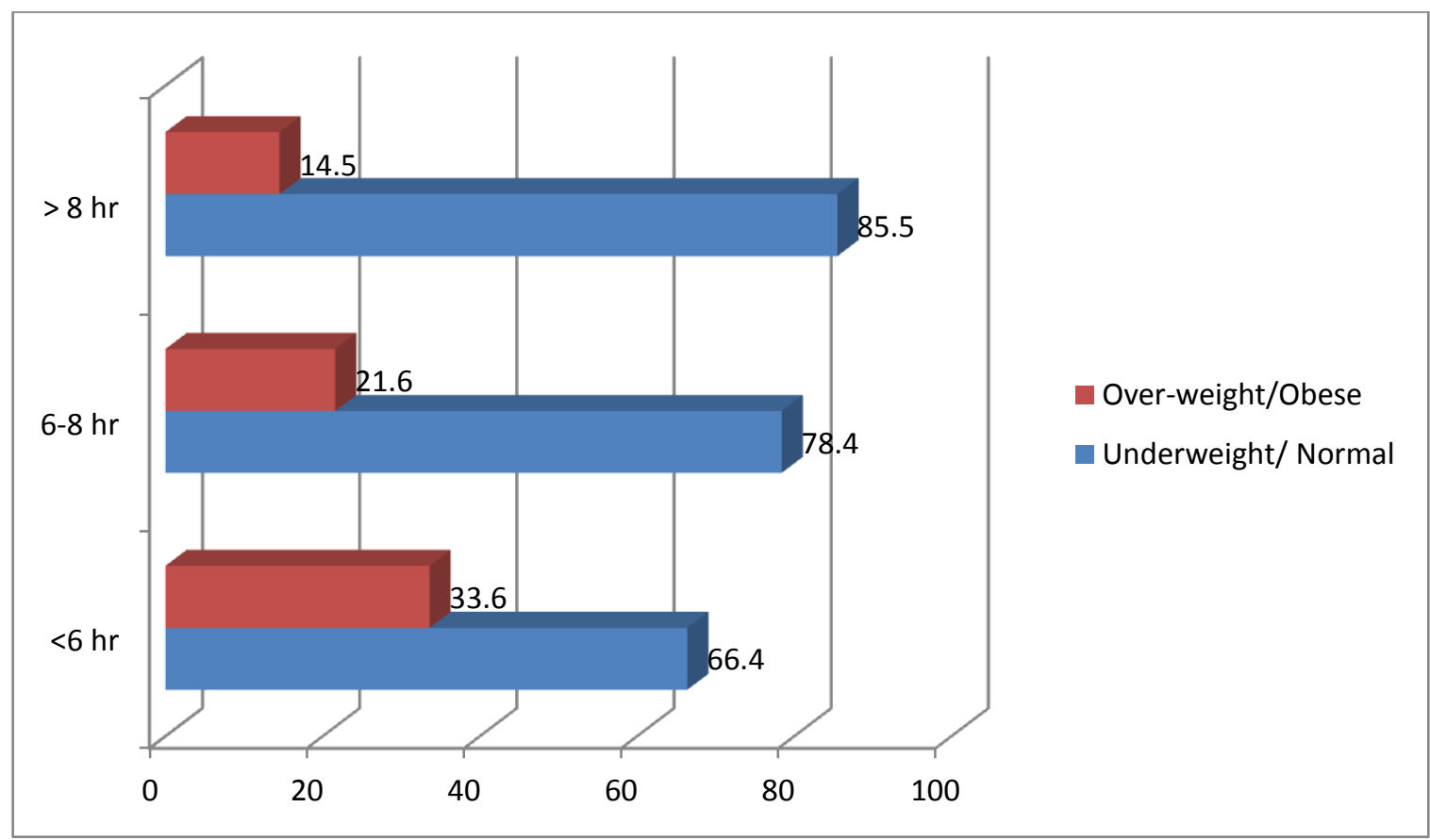

Graph 1 : Association of overweight and obesity with duration of sleep at night.

Among females prevalence of overweight/obesity was found higher $(30.4 \%)$ among those who were sleeping $<6 \mathrm{hr}$ as compare to those who slept more.
(Table 3) and the association was statistically significant ( $\mathrm{P}$ value 0.04166 )

Table 3: Overweight/Obesity and duration of sleep among female subjects

\begin{tabular}{|c|c|c|c|c|c|}
\hline $\begin{array}{l}\text { Duration of night } \\
\text { sleep (hours) }\end{array}$ & $\begin{array}{c}\text { Under-weight / } \\
\text { Normal } \\
(\%) \\
\end{array}$ & $\begin{array}{c}\text { Over-weight } \\
(\%) / \text { Obese } \\
(\%) \\
\end{array}$ & $\begin{array}{c}\text { Total } \\
(\%)\end{array}$ & $\chi^{2}$ & P value \\
\hline$<6 \mathrm{hr}$ & $\begin{array}{c}39 \\
(69.6)\end{array}$ & $\begin{array}{c}17 \\
(30.4)\end{array}$ & 56 & \multirow{4}{*}{8.3129} & \multirow{4}{*}{0.04166} \\
\hline $6-7 \mathrm{hr}$ & $\begin{array}{c}153 \\
(81.4) \\
\end{array}$ & $\begin{array}{c}35 \\
(18.6) \\
\end{array}$ & 188 & & \\
\hline$\geq 8 \mathrm{hr}$ & $\begin{array}{c}101 \\
(87.8) \\
\end{array}$ & $\begin{array}{c}14 \\
(12.2) \\
\end{array}$ & 115 & & \\
\hline $\begin{array}{l}\text { Total } \\
(\%)\end{array}$ & $\begin{array}{c}293 \\
(81.6)\end{array}$ & $\begin{array}{c}66 \\
(25.5)\end{array}$ & 359 & & \\
\hline
\end{tabular}

Among all males subjects prevalence of overweight /obesity was highest $(36.1 \%)$ among those, who sleep $<6 \mathrm{hr}$ and prevalence showed increasing trend with respects to sleep deprivation and difference was also found significant ( $\mathrm{P}$ value 0.038164). (table 4) 
Table 4: Overweight/Obesity and duration of sleep among male subjects

\begin{tabular}{|c|c|c|c|c|c|}
\hline $\begin{array}{lr}\begin{array}{l}\text { Duration } \\
\text { night } \\
\text { (hours) }\end{array} & \begin{array}{r}\text { of } \\
\text { sleep }\end{array}\end{array}$ & $\begin{array}{c}\text { Under-weight / } \\
\text { Normal } \\
(\%)\end{array}$ & $\begin{array}{c}\text { Over-weight } \\
(\%) / \text { Obese } \\
(\%)\end{array}$ & $\begin{array}{l}\text { Total } \\
(\%)\end{array}$ & $\chi^{2}$ & $P$ value \\
\hline$<6 \mathrm{hr}$ & $46(63.9)$ & $26(36.1)$ & 72 & \multirow{4}{*}{6.5317} & \multirow{4}{*}{0.038164} \\
\hline $6-7 \mathrm{hr}$ & 184(76.0) & $58(24.0)$ & 242 & & \\
\hline$\geq 8 \mathrm{hr}$ & $58(81.7)$ & $13(18.3)$ & 71 & & \\
\hline $\begin{array}{l}\text { Total } \\
(\%)\end{array}$ & $288(74.8)$ & 97(25.2) & 385 & & \\
\hline
\end{tabular}

Prevalence of overweight/obesity showed increasing trend with respects to sleep deprivation among both males and females.

\section{Discussion}

Adequate sleep has been considered important for the adolescent's health and well-being. Our study findings indicate that adolescents do not obtain enough daily sleep at night and predisposes to become overweight or obese due to inadequate daily sleep.

This study shows that there is statically significant association between short sleep duration and overweight/obesity.

Tapaswini Mishra et al $^{\mathbf{1 8}}$ in their study showed an association between short sleep duration and obesity which was highly significant. Sanjay R. Patel et $\mathbf{a l}^{19}$ in a systematic review of crosssectional and cohort studies of children found that short sleep duration is strongly and consistently associated with concurrent and future obesity. Results from adult cross-sectional analyses were more mixed with 17 of 23 studies supporting an independent association between short sleep duration and increased weight while all 3 longitudinal studies included in study among adults found a positive association between short sleep duration and future weight. These findings are corroborates with Marshall et $\boldsymbol{a l}^{\mathbf{2 0}}$ (2008). Yadav $\mathbf{N}$ et $\mathbf{a l}^{\mathbf{2 1}}$ also found $19.40 \%$ more chance of overweight /obesity in children sleeping $<6$ at night as compared to those sleeping 6 to 8 hours in night in vicariate analysis.

Xiao $\mathbf{Q}$ et $\mathbf{a l}^{\mathbf{2 2}}$ in different epidemiological study of older adults concluded that sleep duration of less than 5 hours, compared with sleeping 7-8 hours, increased the likelihood of developing obesity. In one meta-analysis of 30 investigations (634 511 participants), a pooled regression analysis in the adults by Cappuccio FP et $\mathbf{~ a l}^{23}$ suggested that a reduction in 1 hour of sleep per day would be associated with a $0.35 \mathrm{~kg} / \mathrm{m} 2$ increase in BMI.

Similar findings were reported by Krutarth $\mathbf{R}$ Brahmbhatt et $\mathbf{a l}^{\mathbf{2 4}}$ where inadequate sleep duration at night was found as a risk factor. Richard Lowry et $\mathbf{a l}^{\mathbf{2 5}}$ also reported sleep durations were associated with increased likelihood of obesity by using logistic regression to control for demographic and behavioural confounders. Cooper $\mathbf{C B}$ et $\mathbf{a l}^{\mathbf{2 6}}$ showed Individuals who regularly slept less than 7 hours per night were more likely to have higher average body mass indexes and develop obesity than those who slept more.

In the current study, significant association was found among both sexes and we did not observe any significant difference in sleep duration between males and females. Such findings are in concordance with those reported by previous research for adolescents from various country like Australia $^{27}$ Switzerland ${ }^{28}$ and Germany ${ }^{29}$.

Although Shivanand Shriram Rathod et al ${ }^{\mathbf{3 0}}$ in their study among medical students found a significant negative association between duration of sleep per night and overweight and obesity. This difference may be due to different sociodemographic profile of individual.

The similar results which shows significant association between short sleep duration and 
overweight/obesity may validate the role of sleep deprivation as an important risk factor for obesity and overweight, independent of increased calorie intake and lack of physical activity ${ }^{19}$.

\section{Conclusion}

There is extensive scientific evidence linking sleep restriction to weight gain and obesity. Although mechanistic relationships are not yet clear Positive correlation was found between decreased sleep duration and tendency to become overweight/obese among adolescents of Rewa city. Statistically significant association was found between short sleep duration and overweight/ obesity among both males and female subjects. However, further research is needed with objective measures of sleep duration and repeated assessments of both sleep duration and body weight is essential. Experimental study designs that manipulate sleep duration are also necessary to better explore the possibility of a causal relationship between sleep deprivation and obesity.

\section{Recommendation}

- Get into bright light as soon as possible in the morning, but avoid in evening Sunlight exposure is a powerful stimulant for regulating the biological clock.

- Establish a regular bedtime and wake time schedule.

- After lunch, stay away from all stimulants ex. caffeinated coffee and colas, nicotine, alcohol.

- Avoid computer games within one hour of going to bed. Don't sleep with the smart phone in your bed.

- Educate teachers, school health providers and other school personnel about adolescent sleep needs and consequences. Integrate sleep-related education in curriculum so that students can learn about the physiology and benefits of sleep and the consequences of sleep deprivation.
- From the parents side, Be a good role model.

\section{Limitation}

The study conducted was cross-sectional observational study, so no causal inference was possible.

Conflict of interest: NIL

\section{References:}

1. Popkin BM. Global nutrition dynamics: The world is shifting rapidly toward a diet linked with non-communicable diseases. Am J Clin Nutr 2006;84:289-98.

2. WHO health topic; nutrition, Available on: https://www.who.int/nutrition/topics /obesity /en/,[Last assesed 1-09-19]

3. Available from: http://www. Iaso .org/iotf/obesity/obesitytheglobalepidemic/ for Saudi, Canada, South Africa, Australia and NZ estimates, accessed on November 22, 2013].

4. SS, Chumlea WC. Tracking of body mass index in children in relation to overweight in adulthood. Am J Clin Nutr 1999;70(1):145S-8.

5. National Sleep Foundation. "Sleep-wake cycle: Its physiology and impact on health". (PDF). National Sleep Foundation; 2006. Available from: https://sleepfoundation.org/sites/default/ files/SleepWakeCycle.pdf.

6. Gangwisch JE, Melaspina D, BodexAlbala B, Heymsfield SB.Inadequate Sleep as a risk factor for Obesity: Analysis of the NHANES I. Sleep 2005;28:1289-96

7. Yu Y, Lu BS, Wang B, Wang H, Yang J, Li Z, et al. Short Sleep Duration And Adiposity In Chinese Adolescents. Sleep 20071; 30:1688-97

8. Snell EK, Adam EK, Duncan GJ. Sleep and the Body Mass Index and Overweight Status of Children and Adolescents. Child Development. 2007;78:309-23. 
9. Schoenborn CA, Adams PE. Health behaviors of adults: United States, 20052007. Vital Health Stat 10. 2010;245:1132

10. SE, Tak S, Calvert GM. The prevalence of short sleep duration by industry and occupation in the National Health Interview Survey. Sleep. 2010;33(2):14959.

11. Knutson KL, Van Cauter E, Rathouz PJ, DeLeire T, Lauderdale DS. Trends in the prevalence of short sleepers in the USA: 1975-2006. Sleep. 2010;33(1):37-45.

12. Sleep statistics,. Available at: https://www.sleepassociation.org/aboutsleep/sleep-statistics/\{ Last assessed on 209-19].

13. Gohil A and Hannon TS (2018) Poor Sleep and Obesity: Concurrent Epidemics in Adolescent Youth. Front. Endocrinol. 9:364. doi: 10.3389/fendo.2018.00364

14. K. Spiegel, R. Leproult, and E. van Cauter, "Impact of sleep debt on metabolic and endocrine function," The Lancet, vol.354, no. 9188, pp. 1435-1439, 199.

15. K. Spiegel, E. Tasali, R. Leproult, and E. van Cauter, "Effects of poor and short sleep on glucose metabolism and obesity risk,"Nature Reviews Endocrinology, vol. 5, no. 5, pp. 253-261, 2009.

16. Institute of Medicine, Sleep Disorders and Sleep Deprivation: An Unmet Public Health Problem, National Academies Press, Washington, DC, USA, 2006.

17. Cole TJ, Bellizzi MC, Flegal KM, Dietz WH. Establishing a standard definition for child overweight and obesity worldwide: International survey. BMJ. 2000 ;320: 1240-3. [PubMed]

18. Mishra T, Mohapatra D, Behera M, MishraS. Association between short sleep and obesity in medical students. Asian J Pharm Clin Res. 2017;10(1):242-4.
19. Patel SR, Hu FB. Short sleep duration and weight gain: A systematic review. Obesity (Silver Spring) 2008;16(3):643-53.

20. Marshall NS, Glozier N, Grunstein RR. Is sleep duration related to obesity? A critical review of the epidemiological evidence. Sleep Med Rev 2008;12(4):289-98.

21. Yadav N 1\$, Yadav S2, Relation between Changing Lifestyle and Adolescent Obesity in India: A Community Based Study among School Children, IMJH, Vol1, Issue-10, Dec.- 2015

22. Xiao Q, Arem H, Moore SC, et al. A large prospective investigation of sleep duration, weight change, and obesity in the $\mathrm{NIH}$ AARP Dietand Health Study cohort. Am J Epidemiol 2013;178:1600-10

23. Cappuccio FP, Taggart FM, Kandala NB, et al. Meta-analysis of short sleep duration and obesity in children and adults. Sleep 2008;31:619-26

24. Krutarth R Brahmbhatt, Umesh N Oza, Obesity among adolescents of ahmedabad city, gujarat, india- a community based cross-sectional study, Int J Biol Med Res. 2012; 3(2): 1554-1557

25. Richard Lowry, Danice K. Eaton,Kathryn Foti, Lela Mc Knight-Eily, Geraldine Perry,and Deborah A. Galuska, Association of Sleep Duration with Obesity among US High School Students, Journal of Obesity Volume 2012, Article ID 476914

26. Cooper CB,Neufeld EV, Dolezal BA, et al. Sleep deprivation and obesity in adults: a brief narrative review. BMJ Open Sport \& Exercise Medicine 2018;4:e00392. doi:10.1136/bmjsem-2018-000392

27. Olds T, Maher C, Blunden S, Matricciani L. Normative data on the sleep habits of Australian children and adolescents. Sleep 2010;33(10):1381-8.

28. Iglowstein I, Jenni OG, Molinari L, Largo RH. Sleep duration from infancy to adolescence: Reference values and 
generational trends. Pediatrics 2003; 111(2):302-7.

29. Hitze B, Bosy-Westphal A, Bielfeldt F, Settler U, Plachta-Danielzik S, Pfeuffer M, et al. Determinants and impact of sleep duration in children and adolescents: Data of the Kiel Obesity Prevention Study. Eur J Clin Nutr 2009;63(6):739-46.

30. Rathod SS, Nagose VB, Kanagala A, Bhuvangiri H, Kanneganti J, Annepaka E. Sleep duration and its association with obesity and overweight in medical students: A cross-sectional study. Natl J Physiol Pharm Pharmacol 2018;8(1):113117. 